\title{
Bilateral internuclear ophthalmoplegia in multiple sclerosis
}

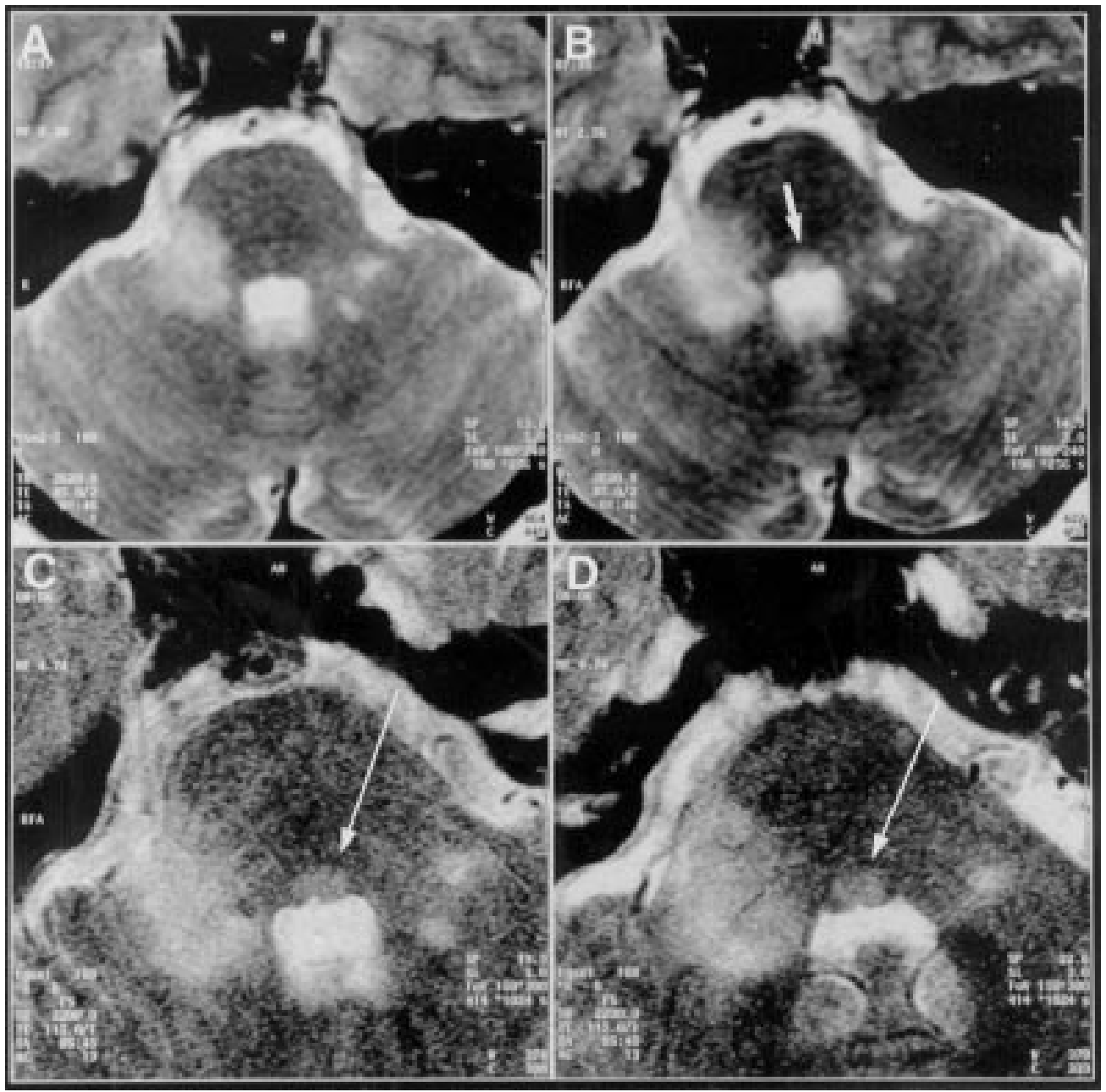

A 35 year old woman with clinically definite early relapsing-remitting multiple sclerosis was readmitted for the second acute relapse within four weeks. Since her recent admission there had been worsening of right facial sensory loss, she had developed a hemiparesis on the right, and complained of an alteration of her vision. On examination there was bilateral internuclear ophthalmoplegia with horizontal and pronounced abnormality of vertical eye movement (impaired vertical pursuit and gaze evoked vertical nystagmus), whereas oculomotor examination had previously been normal.

On fast T2 weighted MRI a lesion at the midpontine level involving the area of the medial longitudinal fascicle (arrow) bilaterally was demonstrated (figure, B), which had not been present 21 days previously (figure, A). On high resolution images (Turbo Gradient Spin Echo, matrix $414 \times 1024$, voxel size $0.36 \mathrm{~mm} \times 0.29 \mathrm{~mm} \times 3 \mathrm{~mm}$, aquisition time $5: 45 \mathrm{~min}$ ) (figure, $\mathrm{C}, \mathrm{D}$ ) the lesion seems to be restricted to both medial longitudinal fascicles, only involving the usually densely myelinated fibres of the medial longitudinal fascicle (arrows).

A GASS

M G HENNERICI

Department of Neurology, Klinikum Mannheim, University of Heidelberg, FR Germany

Correspondence to: Dr A Gass, Department of Neurology, Klinikum Mannheim,

Theodor Kutzer Ufer, 68137 Mannheim, FR Germany. 